\title{
Testing Neurotransmitters for Toxicity with a Luminescent Biosensor: Implications for Microbial Endocrinology
}

\author{
Alexander V. Oleskin ${ }^{1, *}$, Elena V. Sorokina ${ }^{2}$, Alevtina P. Zarubina ${ }^{3}$ and \\ Inna M. Parkhomenko ${ }^{4}$
}

${ }^{1}$ Doctor of Biological Sciences, Professor, Department of General Ecology, School of Biology, Lomonosov

Moscow State University, Moscow, Russia

${ }^{2}$ School of Biology, Lomonosov Moscow State University, Moscow, Russia

${ }^{3}$ Department of Microbiology, School of Biology, Lomonosov Moscow State University, Moscow, Russia

${ }^{4}$ Department of Biophysics, School of Biology, Lomonosov Moscow State University, Moscow, Russia

\begin{abstract}
Background: The human organism is a complex superorganism including numerous eukaryotic, eubacterial, and archaean cells. The qualitative and quantitative assessment of the microbiota toxicity of chemical agents, i.e., their inhibitory effects on the microbial inhabitants of the human organism in health and disease, seems to hold much value in this context. In this work, a bacterial luminescence-based express test system for microbiota toxicity is applied to neurotransmitters such as serotonin, dopamine, norepinephrine, and histamine.

Methods: The biosensor was based on a GM Escherichia coli K12 strain (TGI) that contained the lux operon of the luminescent soil bacterium Photorhabdus luminescencens ZMI. The biosensor was exposed to the action of the tested neurotransmitters for 5 to 60 minutes The intensity of bacterial luminescence (counts $\mathrm{sec}^{-1}$ ) was monitored in the control and the experimental samples with a Biotoks $6 \mathrm{~ms}$ luminometer (Russia); the toxicity index $(T)$ of the neurotransmitters was determined.

Results: A marked toxic effect on bioluminescence was produced by serotonin, histamine, and dopamine at concentrations exceeding $80 \mu \mathrm{g} / \mathrm{ml}, 100 \mu \mathrm{g} / \mathrm{ml}$, and $1 \mathrm{mg} / \mathrm{ml}$, respectively. At lower concentration, these neurotransmitters were "negatively toxic", i.e. stimulatory in terms of the effect on bacterial luminescence. In contrast, norepinephrine inhibited luminescence at all concentrations tested.
\end{abstract}

Conclusions: The bacterial luminescence-based testing method is applicable to the assessment of the destructive and stimulatory effects of neurotransmitters; the data obtained are of microbiological and clinical relevance.

Keywords: Bioassay, bioluminescence, toxicity, neurotransmitters, serotonin, dopamine, histamine, norepinephrine.

\section{INTRODUCTION}

In light of recent data and concepts, the human organism is to be regarded as a complex "superorganism", i.e. a symbiotic system including numerous eukaryotic, eubacterial, and archaean cells as well as viruses. Symbiotic microorganisms are invariably present on the skin, the eye conjunctiva, and the mucosa of the upper airways and the urogenital tract. However, it is the microbiota of the gastrointestinal (GI) tract that is particularly abundant and diverse. The $\mathrm{Gl}$ microbiota is directly involved in nutrient digestion, xenobiotic metabolism, intestinal motility regulation, resistance to gut colonization by extraneous microorganisms including pathogens [1-3]. Detrimental chemical factors and stressors, if applied at destructive (above-threshold) doses and for inadequate

*Address of correspondence to this author at the Department of General Ecology, School of Biology, Lomonosov Moscow State University, Moscow, Russia; Tel: +7903-507-2258; E-mail: aoleskin@rambler.ru periods of time, may cause various microecological disorders, increasing the risk of a large number of pathological syndromes and diseases including diabetes, obesity, asthma, cancer, and neuropsychological problems such as, e.g., autism [3]. Therefore, of paramount importance is developing an adequate and reliable test for the purpose of qualitatively and quantitatively assessing the microbiota toxicity of chemical agents, i.e., their inhibitory effects on the microbial inhabitants of the human organism in health and disease.

One of the widely used biological tests for the primary assessment of the effects of chemicals, their mixtures, and physical factors is based upon bacterial luminescence [4-6]. Intact cells of luminescent bacteria are used in this test, and one of its advantages is that it enables estimating the response to the tested factor on the basis of luminescence intensity. Its level is directly correlated with the bacterial cells' metabolic state. The inverse relationship between bacterial luminescence 
intensity and toxic agent concentration is monitored [78]. The employment of the bioluminescence-based test system as a bioassay tool is facilitated by a number of its advantageous features: the system is technically simple and easy to use, the assay is quick, its costs are low, the results are in conformity with bioassay data obtained using higher animals as test subjects [7, 9]. Therefore, data on microbiota toxicity are to a large extent concordant with those on integral biological toxicity. Of particular importance is the bio-assessment of the group of substances called neurotransmitters with respect to their microbiota toxicity.

Apart from transmitting impulses from neuron to neuron, these biologically active substances perform a wide variety of regulatory functions in diverse biological systems ranging from microbial cells to the human gastro-intestinal (GI) tract. They significantly influence human neurophysiology, health, and psyche [10-12]. The effects of neurotransmitters on microbial systems are also of much intetest. These effects are either inihibitory or stimulatory. Stimulatory activity with respect to microorganisms may be referred to as negative microbiota toxicity. Negative toxicity with regard to the bacterium Escherichia coli was revealed with nano- and micromolar concentrations of dopamine, norepinephrine, serotonin, and histamine [13]. Increasing the concentration of, e.g., serotonin results in changing the toxicity sign: it becomes positive, i.e., high serotonin concentration suppress, and not stimulate, E. coli growth [14].

The importance of rapid reliable assessment methods for neurotransmitters is highlighted by the fact that neurotransmitters are widely used in practice as neurotropic drugs that are exemplified by acetylcholine, norepinephrine, dopamine, and $\gamma$-aminobutyric acid (GABA). These assessment methods would enable us to select the most active preparations and to estimate their therapeutically efficient and toxic concentrations. Presently, it is imperative that highly sensitive tests for evaluating the biological activities and elucidating functionally important properties of natural and synthetic pharmacologically active compounds should be developed. Such tests could be applied, apart from pharmaceutical industry, to the bio-assessment of industrially and domestically used chemicals and to the evaluation of the environmental situation.

The goal of this work was to test the applicability of a bacterial luminescence-based express bioassay to the assessment of the effects of various concentrations of neurotransmitters such as serotonin, dopamine, norepinephrine and histamine-in terms of their microbiota toxicity.

\section{MATERIALS AND METHODS}

In this work, we used the genetically engineered strain Escherichia coli $\mathrm{K} 12 \mathrm{TGI}$ as the biosensor. Its luminescent phenotype was created by cloning the lux operon of the luminescent soil bacterium Photorhabdus luminescencens ZMI in this E. coli strain. The strain was obtained from the Microbiology Department of the School of Biology, Moscow State University. It is known as the biosensor of the Ecolyum-08 test system [15]. In this study, freeze-dried biosensor cells were rehydrated in cold distilled water for 30 minutes. The working suspension contained $2.3-2.7 \times 10^{7}$ cells $/ \mathrm{ml}$.

The density of the bacterial suspension was determined nephelometrically $(\lambda=670 \mathrm{~nm}$ ) with a KF77 photoelectrocolorimeter, and the number of cells per $\mathrm{ml}$ was determined by plotting a calibration curve. The $\mathrm{pH}$ values of aqueous test samples were determined potentiometrically.

Analytic grade serotonin creatinine sulfate, dopamine hydrochloride, norepinephrine hydrochloride, and histamine hydrochloride (Sigma, USA) were used in this work; their concentrations were calculated based on the content of the base form of the respective neurotransmitter in each of the chemicals.

To determine the toxicity index of the aqueous solutions of the neurotransmitters, $0.1 \mathrm{ml}$ of the bacterial biosensor suspension were applied to $1.5 \mathrm{ml}$ flasks; $0.9 \mathrm{ml}$ of sterile distilled water or of the sample solution was added to the control and the experimental flasks, respectively.

The intensity of bacterial luminescence (counts / sec) was concomitantly monitored in the control and the experimental samples with a Biotoks 6 luminometer (Russia) at room temperature $\left(20-22{ }^{\circ} \mathrm{C}\right)$; the biosensor was exposed to the action of the tested neurotransmitters for 5 to 60 minutes. The toxicity index $(T)$ of the neurotransmitters was determined automatically by the luminometer that was programmed to use the formula:

$$
\mathrm{T}=100 \times(\mathrm{lk}-\mathrm{I}) / \mathrm{lk},
$$

where $I_{k}$ and $I$ are the illumination intensity of the control and the experimental samples, respectively. The tested neurotransmitters were classified into three groups according to their toxicity level: $T<20$, the agent is non-toxic; $T>20<50$, the agent is toxic; $T>50$, the 
agent is very toxic [7, 15]. In some studies, the stimulation of luminescence of the test organism occurred, and the $T$ value was considered to be negative. In addition to the toxicity index, we measured the concentrations that caused $20 \%$ and $50 \%$ inhibition of bacterial luminescence (EC, intensity of luminescence, which varies depending on the concentration of the substance or its volume). The value of $\mathrm{EC}_{20}$ is usually referred to as the lower "threshold" toxicity value. The $\mathrm{EC}_{50}$ value of a substance was found to be correlated with its $L_{50}$ value with respect to higher animals [7, 9].

The results of the studies were treated statistically. The reliability of the differences between experimental and control values was assessed using the t-Student criterion.

\section{RESULTS AND DISCUSION}

The bacterial luminescence-based bioassay enabled us to estimate the effects of neurotransmitters after different exposure periods (Figures 1-4). Serotonin and dopamine exerted a stimulatory effect (Figures 1 and 2) at concentrations up to $10 \mu \mathrm{g} / \mathrm{ml}$, i.e., approximately $50 \mu \mathrm{M}$. The serotonin effect on biosensor luminescence proved to be analogous to that on biomass accumulation, colony-forming unit (CFU) generation, and cell aggregation in E. coli. All these processes were stimulated by serotonin at concentrations below $20 \mu \mathrm{M}$ and inihibited by higher serotonin concentrations [13,14]. Since high serotonin concentrations (> $50 \mu \mathrm{M})$ also suppressed the generation of membrane potential by bacterial membranes, the inhibitory effect of serotonin was attributed to its uncoupling activity with respect to membrane phosphorylation [14]. Analogous uncoupling activity is possible for the other tested amines that also contain an ionizable amino group in the vicinity of the aromatic ring.

Histamine stimulated the biosensor's luminescence at a concentration of $25 \mu \mathrm{g} / \mathrm{ml}$, i.e., $200 \mu \mathrm{M}$ (Figure 3). Norepinephrine inhibited bioluminescence at all tested concentrations (Figure 4). For each of the neurotransmitters, we determined the non-toxic, toxic, and highly toxic concentration ranges. Serotonin was non-toxic within the $1-60 \mu \mathrm{g} / \mathrm{ml}$ concentration range; the toxicity index was $\sim 20$.

Histamine was not toxic unless its concentrations exceeded $50 \mu \mathrm{g} / \mathrm{ml}$. Norepinephrine was toxic at all tested concentrations. High toxicity ( $T>50$ ) was observed after incubating the biosensor with at least 1 $\mathrm{mg} / \mathrm{ml}$ of serotonin for $5 \mathrm{~min}$. The toxicity of dopamine and histamine increased gradually with an increase in exposure time; it reached the maximum level after 60 minutes of incubation with the biosensor. Histamine at a concentration of minimally $100 \mu \mathrm{g} / \mathrm{ml}$ was highly toxic.

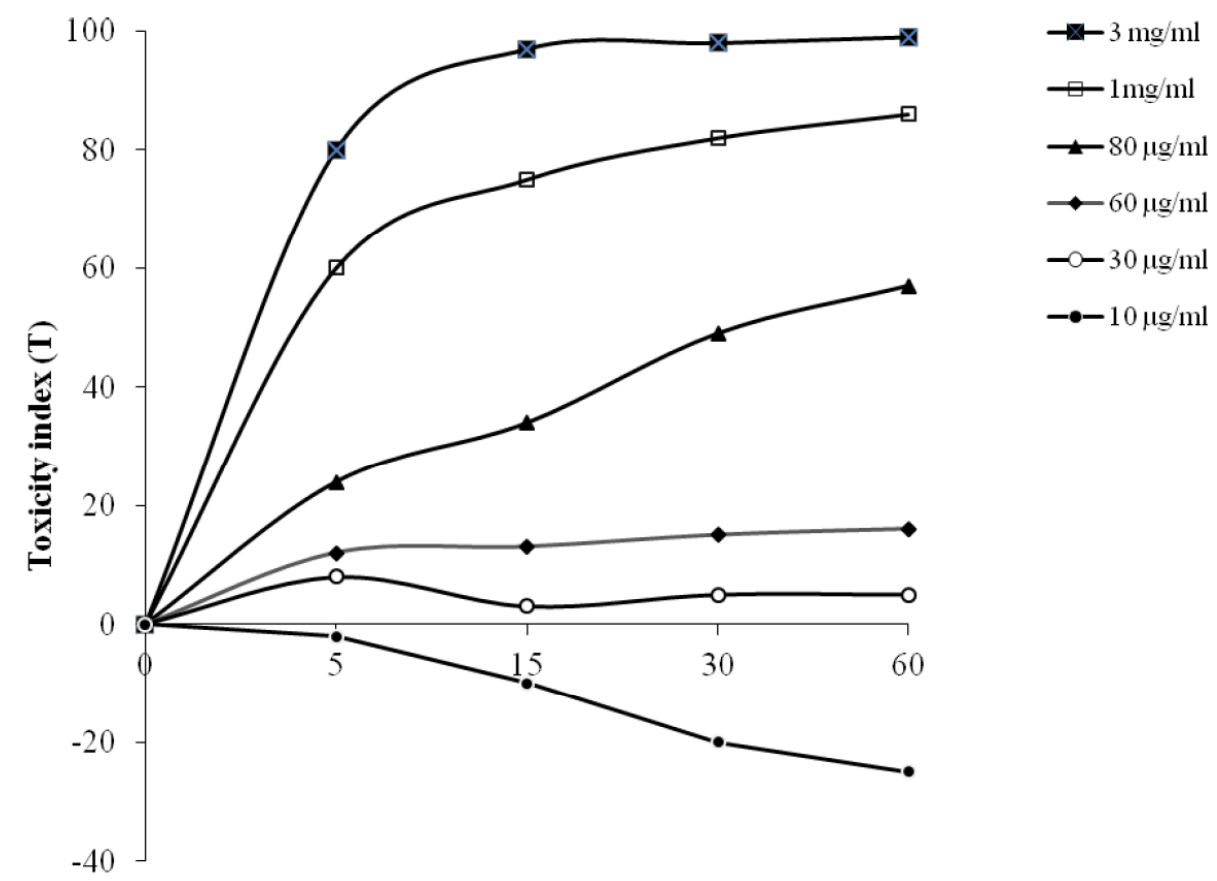

Time, min

Figure 1: Toxicity of various serotonin concentrations in the bacterial luminescence-based test system plotted against exposure time. 


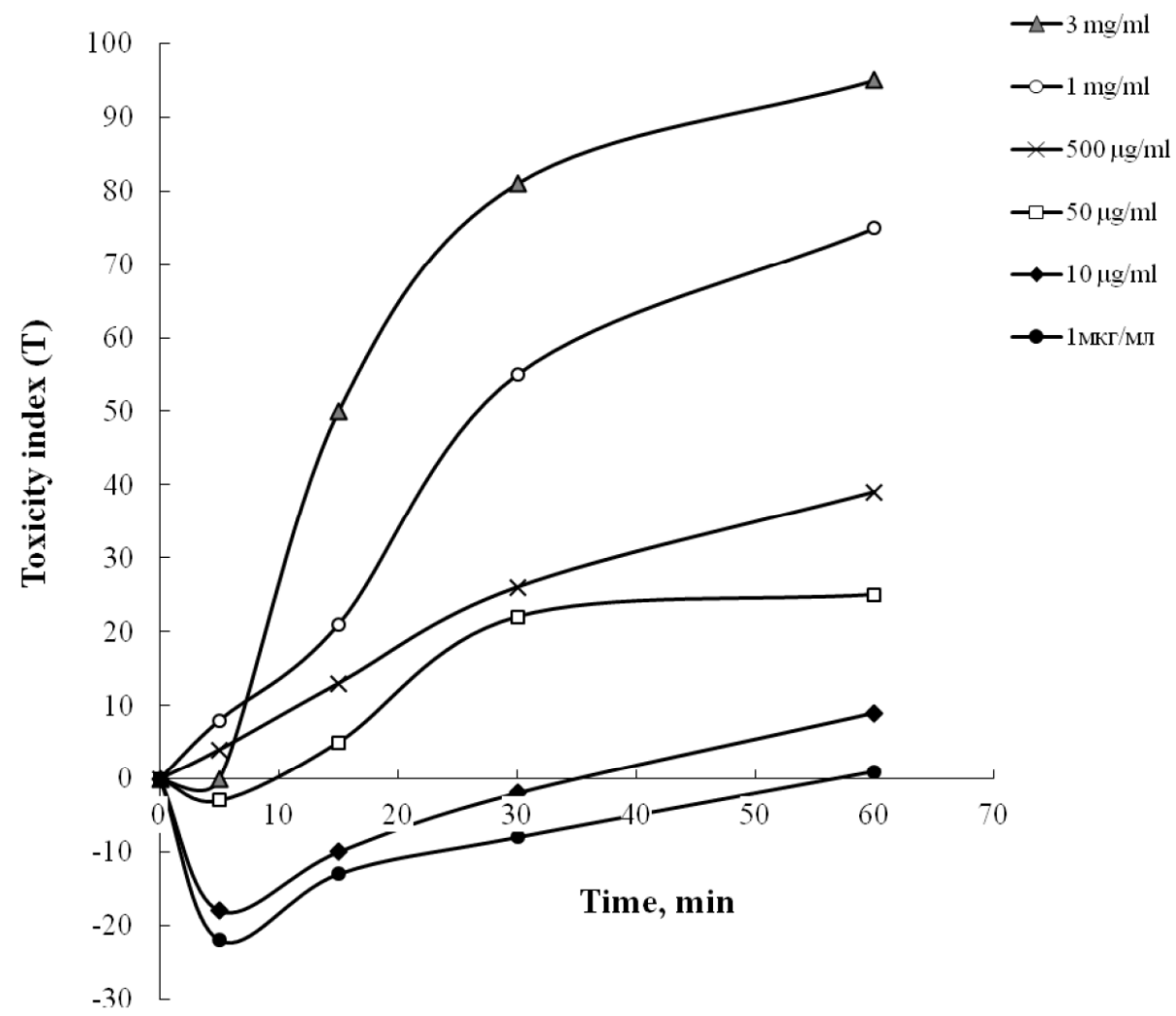

Figure 2: Toxicity of various dopamine concentrations in the bacterial luminescence-based test system plotted against exposure time.

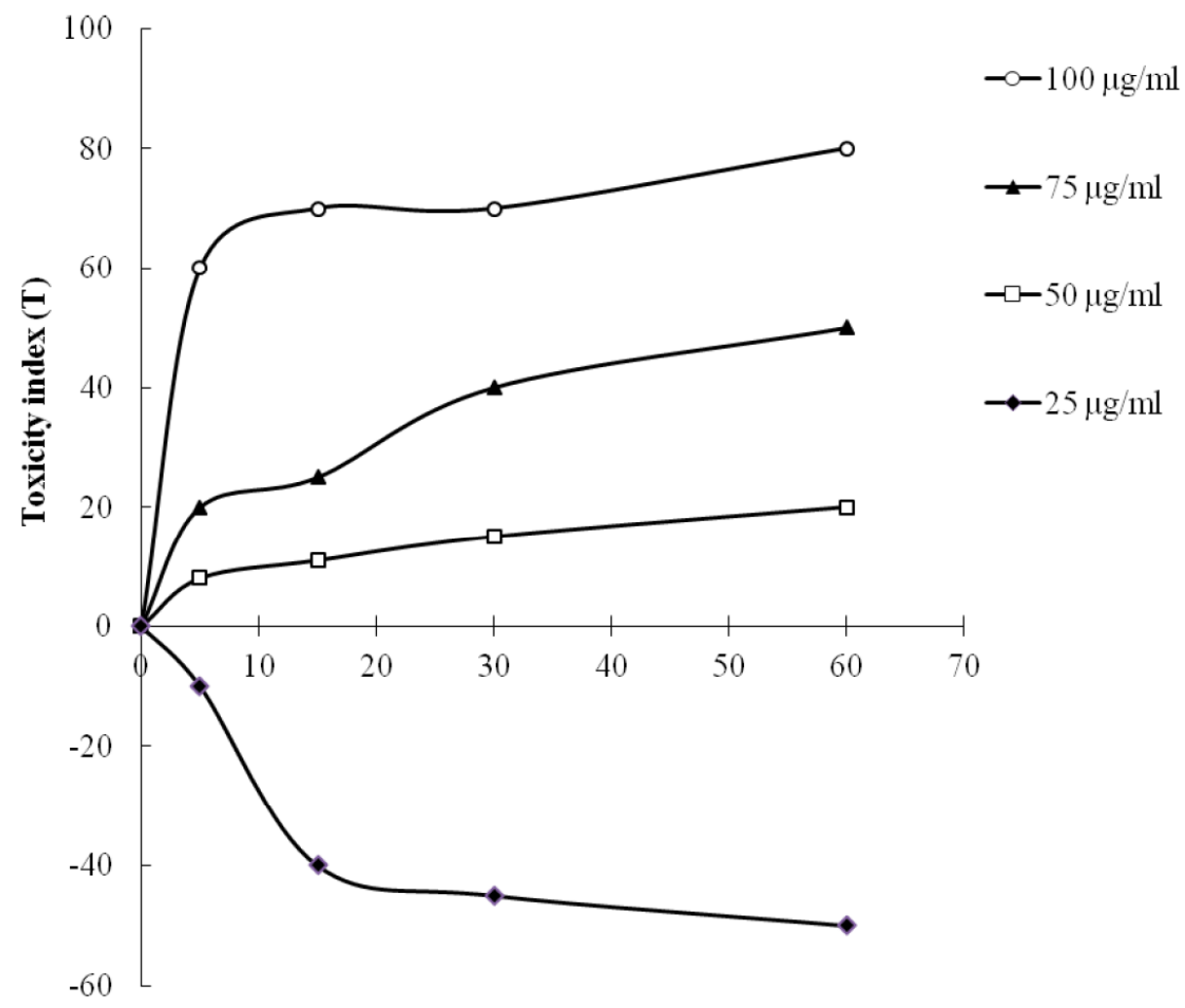

Time, min

Figure 3: Toxicity of various histamine concentrations in the bacterial luminescence-based test system plotted against exposure time. 


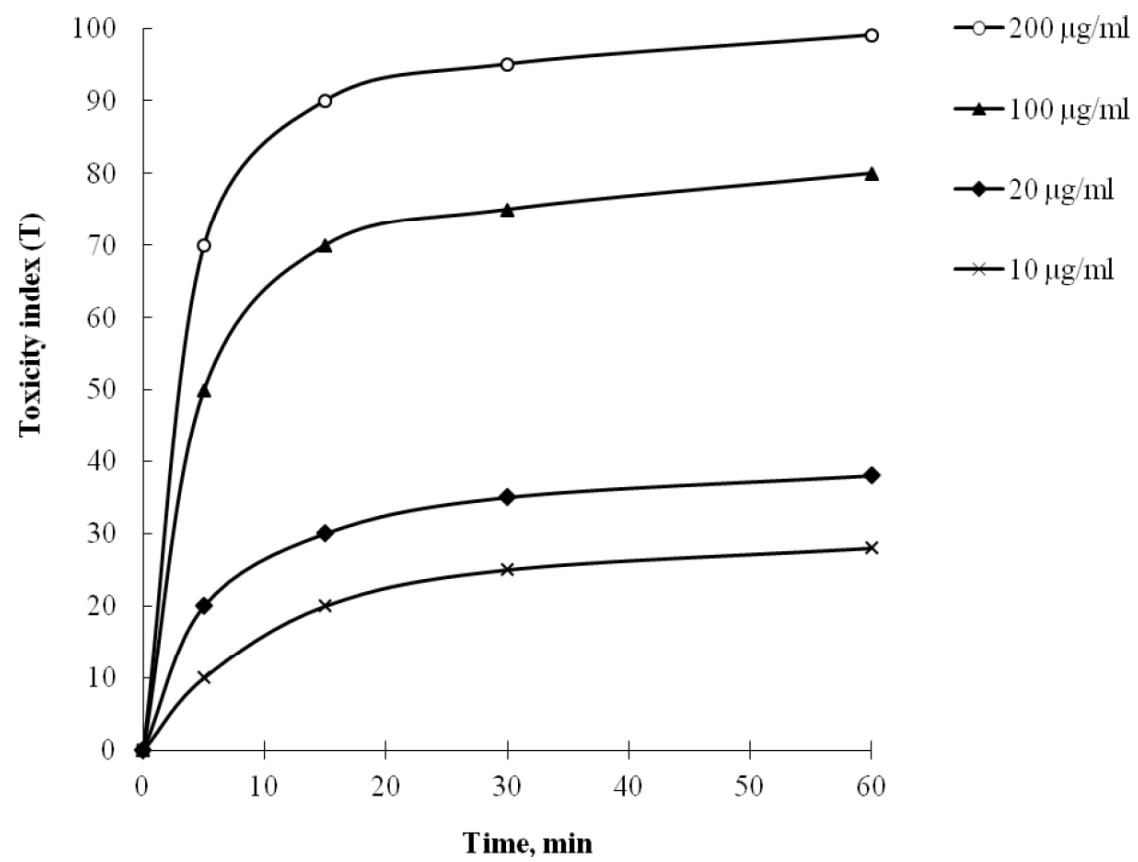

Figure 4: Toxicity of various norepinephrine concentrations in the bacterial luminescence-based test system plotted against exposure time.

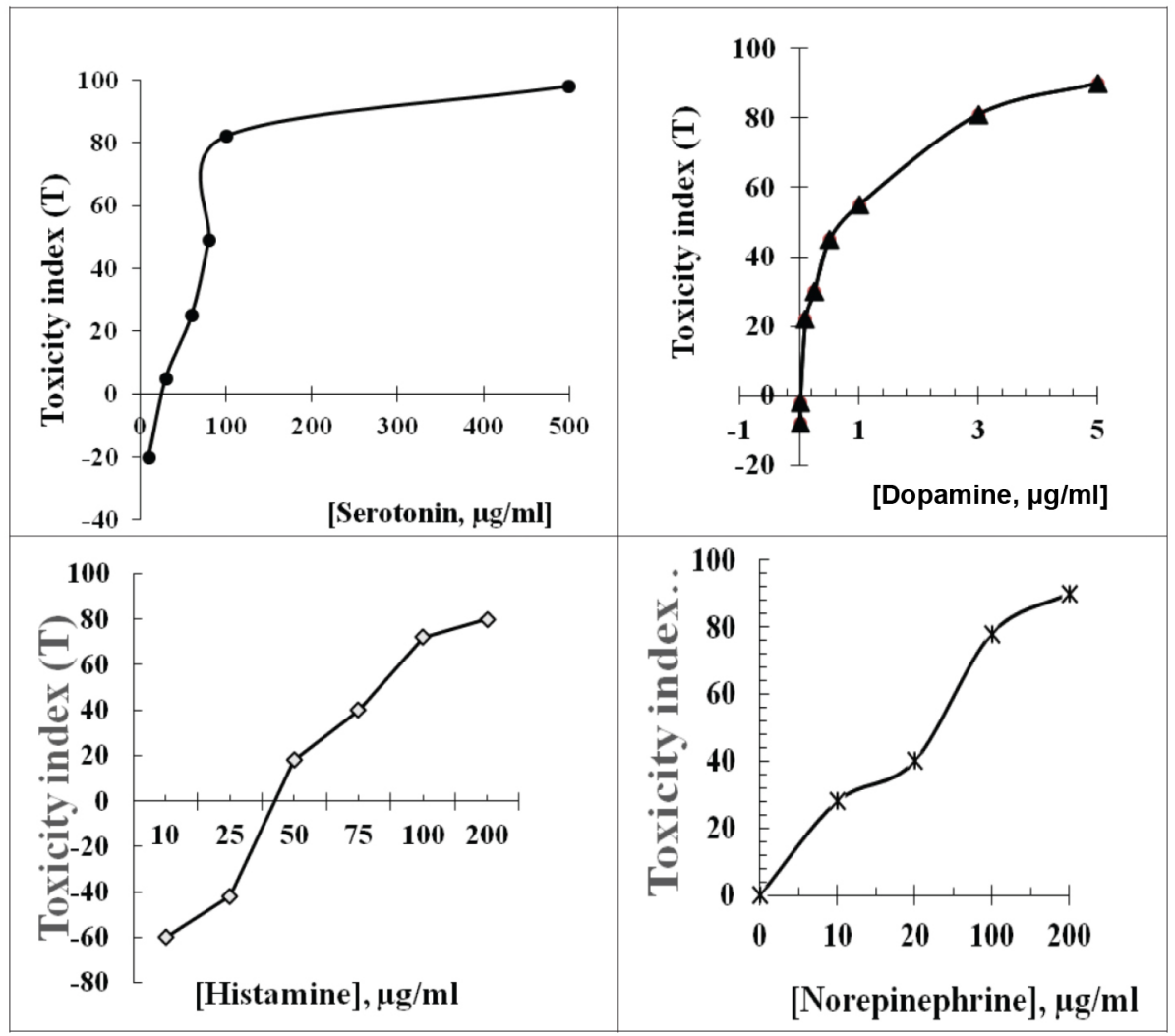

Figure 5: Toxicity indices of the tested neurotransmitters applied at various concentrations after 30 mins of incubation with the biosensor.

The data on the toxicity indices of the tested neurotransmitters at a biosensor exposure time of 30 min are in Figure 5. They enable us to estimate the activity of the neurotransmitters under study and to compare them.
The $\mathrm{EC}_{20}$ and $\mathrm{EC}_{50}$ values were calculated for the tested range of neurotransmitter concentrations. It was revealed that dopamine was the least toxic $\left(E_{20} \sim 100\right.$ $\mu \mathrm{g} / \mathrm{ml} ; \mathrm{EC}_{50} \sim 500 \mu \mathrm{g} / \mathrm{ml}$ ), and norepinephrine the most toxic agent $\left(\mathrm{EC}_{20} \sim 5 \mu \mathrm{g} / \mathrm{ml} ; \mathrm{EC}_{50} \sim 40 \mu \mathrm{g} / \mathrm{ml}\right)$. The 
corresponding values for serotonin $\left(\mathrm{EC}_{20} \sim 45 \mu \mathrm{g} / \mathrm{ml}\right.$; $\left.\mathrm{EC}_{50} \sim 80 \mu \mathrm{g} / \mathrm{ml}\right)$ and histamine $\left(\mathrm{EC}_{20} \sim 57 \mu \mathrm{g} / \mathrm{ml} ; \mathrm{EC}_{50}\right.$ $\sim 85 \mu \mathrm{g} / \mathrm{ml}$ ) are also shown in Table 1.

Table 1: $E_{20}$ and $E C_{50}$ Values of the Tested Neurotransmitters

\begin{tabular}{|c|c|c|}
\hline Neurotransmitters & $\mathrm{EC}_{\mathbf{2 0}}, \boldsymbol{\mu \mathbf { g } / \mathbf { m l }}$ & $\mathrm{EC}_{\mathbf{5 0}}, \boldsymbol{\mu \mathbf { g }} \mathbf{\mathbf { m l }}$ \\
\hline \hline Serotonin & 45 & 80 \\
\hline Dopamine & 100 & 500 \\
\hline Histamine & 57 & 85 \\
\hline Norepinephrine & 5 & 40 \\
\hline
\end{tabular}

The $\mathrm{EC}_{20}$ value is routinely referred to as the lower threshold value of toxicity, where as the $\mathrm{EC}_{50}$ value is correlated with the $L D_{50}$ level in higher animals. A large number of previous bioassay studies on the toxicity indices of diverse xenobiotics revealed a relationship between the luminescence quenching $\mathrm{EC}_{50}$ value in the biosensor model and the corresponding $L D_{50}$ value for eukaryotic organisms. The correlation coefficient is 0.8 to $0.95[7,9]$.

In terms of bio-toxicity, our results indicate that the tested neurotransmitters can be arranged in the following order:

norepinephrine $>$ serotonin $\approx$ histamine $>$ dopamine [16-18].

For comparison, the literature data on the per os toxicity of biogenic amines for the mouse are as follows (Table 2).

Table 2: $L_{50}$ Values of the Neurotransmitters for the Mouse [19-21]

\begin{tabular}{|c|c|}
\hline neurotransmitter & LD $_{\mathbf{5 0}}, \mathbf{m g} \mathbf{k g}$ (per os administration) \\
\hline \hline Serotonin & 220 \\
\hline Dopamine & 1640 \\
\hline Histamine & 220 \\
\hline Norepinephrine & 26 \\
\hline
\end{tabular}

According to recent literature data, biogenic amines are synthesized and accumulated in microbial cells, including those of $E$. coli, even if the cultivation medium does not contain them. These concentrations are sufficiently high to enable their binding to receptors in animal /human cells $[3,19]$. Possibly, the effects that were observed in our test system resulted from the combined action of both exogenous and endogenous (biosensor cell-synthesized) neurotransmitters.
Of much interest are our results on the difference between the toxicity of dopamine and norepinephrine in conjunction with the data on their biological effects [2021]. Structurally, it is only the presence of an additional hydroxyl radical that distinguishes the molecule of norepinephrine from that of dopamine. Norepinephrine performs important functions in the brain and the sympathetic branch of the peripheral nervous system; there is a long biosynthetic pathway that leads from phenylalanine and tyrosine to dopamine. Under the catalytic influence of $\beta$-hydroxylase, dopamine converts to norepinephrine. Taking into account the difference between the effects of the two chemically similar compounds, we suggest that these effects at least partly result from specific interactions involving receptors on the surface of microbial cells that individually recognize neurotransmitters. We demonstrated in our recent studies that dopamine stimulated cell proliferation in the eukaryote Saccharomyces cerevisiae, while norepinephrine did not significantly influence this process. The dopamine agonist apomorphine that binds to receptors $D_{1}$ and $D_{2}$ also was found to stimulate cell proliferation $[18,19]$.

Thus, the bioassay method that is based on the bacterial luminescence model can be applied for the evaluation of the biological effects of stimulatory and inhibitory concentrations of natural and synthetic neurochemicals. Biogenic amines produce analogous effects on biosensor cell luminescence and on the growth parameters and physiological characteristics of bacterial cells (see the authors' earlier research, [13, 14]), This fact emphasizes that the information obtained with the bioluminescence test is of primary relevance to the physiological effects of neurotransmitters, including their impact on the human microbiota. Therefore, our test technique and the data obtained with its help seem to be of considerable importance with regard to future research concerning human physical and mental health.

\section{CONFLICT OF INTEREST DISCLOSURES}

The authors do not have any conflicts of interest.

\section{REFERENCES}

[1] Shenderov BA. Microbial ecology and its role in promoting health. Metamorfozy (Russian) 2014; 5: 72-80.

[2] El Aidy S, Dinan TG, Cryan JF. Gut microbiota: the conductor in the orchestra of immune-neuroendocrine communication. Clin Ther 2015; 37: 954-67. https://doi.org/10.1016/j.clinthera.2015.03.002

[3] Krishnan S, Alden N, Lee K. Pathways and functions of gut metabolism impacting host physiology. Curr Opin Biotech 2015; 36: 137-45.

https://doi.org/10.1016/j.copbio.2015.08.015 
[4] Zarubina AP, Sorokina EV. First among equals. The bacterial luminescence test: one of the quickest and easiest bioassays. J Eurasian Researcher Union Biol Ser (Russian) 2015; 17(8): 161-3.

[5] Zarubina AP, Perfiliev YD, Sorokina EV, et al. Evaluation of the properties of potassium ferrate used for water purification by luminescence bioassay. Mosc Univ Biol Bull 2016; 71(4): 226-30. https://doi.org/10.3103/S0096392516040131

[6] Zarubina AP, Gapochka MG, Novoselova LA, et al. Effect of low intensity electromagnetic radiation on the toxicity of domestic wastewater tested with the «ecolum» test system. Mosc Univ Biol Bull 2013; 68(1): 49-52. https://doi.org/10.3103/S0096392512030108

[7] Bulich AA, Tung KK, Scheibner G. The luminescent bacteria toxicity test: its potential use as an in vitro alternative. Biolum Chemilum 1990; 5(2): 71-77. https://doi.org/10.1002/bio.1170050202

[8] Zarubina AP, Deev LI, Parkhomenko IM, et al. Evaluation of toxicity of argentum ions and nanoparticles on the model bacterial object with luminescent phenotype. Nan Sci Rus 2015; 10(5-6): 475-83.

[9] Kaiser KL. Correlation of Vibrio fischeri bacteria test data with bioassay data for other organisms. //Environ Health Persp 1998; 106(2): 583-91. https://doi.org/10.1289/ehp.98106583

[10] Ashmarin IP, Eshchenko ND, Karazeeva EP Neurochemistry in tables and diagrams. Moscow: Exam 2007.

[11] Vasiliev VN Diagnosis and treatment of incurable nervous and mental diseases of dopamine etiology. Moscow: Media Kit; 2009.

[12] Oleskin AV, El'-Registan GI, Shenderov BA. Role of neuromediators in the functioning of the human microbiota: «business talks» among microorganisms and the microbiotahost dialogue. Microbiology 2016; 85(1): 1-22. https://doi.org/10.1134/S0026261716010082

[13] Anuchin AM, Chuvelev DI, Kirovskaya TA, et al. Effect of neuromediator monoamines on the growth characteristics of Escherichia coli K-12. Microbiology 2008; 77(6): 758-765. https://doi.org/10.1134/S0026261708060040
[14] Oleskin AV, Kirovskaya TA, Botvinko IV, et al. Effect of serotonin (5-hydroxytryptamine) on the growth and differentiation of microorganisms. Microbiology 1998; 67(3): 306-31.

[15] Danilov VS, Zarubina AP, Eroshnicov GE, et al. The biolumiscent sensor systems with lux operons from various species of luminescent bacteria. Mosc Univ Biol Bull 2002; 57(3): 20-4.

[16] De Backer D, Biston P, Devriendt J, et al. Comparison of dopamine and norepinephrine in the treatment of shock. New Engl J Med 2010; 362(9): 779-89. https://doi.org/10.1056/NEJMoa0907118

[17] Inoue W, Baimoukhametova D.V, Füzesi T, et al. Noradrenaline is a stress-associated metaplastic signal at GABA synapses. Nat Neurosci 2013; 16(5): 605-12. https://doi.org/10.1038/nn.3373

[18] Oleskin AV, Shishov VI, Malikina KD. Symbiotic biofilms and brain neurochemistry. Hauppage (NY): Nova Science Publishers 2010.

[19] Malikina KD, Shishov VA, Chuvelev DI, et al. Regulatory role of neuromediator amines in Saccharomyces cerevisiae cells. Appl Biochem Micro 2010; 46(6): 672-7. https://doi.org/10.1134/S0003683810060104

[20] Xue R, Zhang YP, Jin ZL, et al. The discovery of 071031B, a novel serotonin and noradrenaline reuptake inhibitor. Neurosci Lett 2013; 544(1): 68-73. https://doi.org/10.1016/j.neulet.2013.02.076

[21] Isbister GK, Bowe SJ, Dawson A, et al. Relative toxicity of selective serotonin reuptake inhibitors (SSRIs) in overdose. J Toxicol-Clin Toxic 2004; 42(3): 277-85. https://doi.org/10.1081/CLT-120037428

[22] Sarkar C, Basu B, Chakroborty D, et al. The immunoregulatory role of dopamine: an update. Brain Behav Immun 2010; 24(4): 525-8.

https://doi.org/10.1016/j.bbi.2009.10.015

[23] Sconbaume E, Sellers EA, Johnson GE. Noradrenaline and survival of rats in a cold environment. Can J Biochem Phys 1963; 41: 975-83.

https://doi.org/10.1139/063-111 